\title{
3d Modelling of Structures using terrestrial laser scanning technique
}

\author{
Oseni A.E.*, Ajani O. K., Adewale A.J, Ayodeji O.O, Desalu T.O ${ }^{4}$
}

Department of Surveying \& Geoinformatics, Faculty of Engineering, University of Lagos, Akoka, Lagos State, Nigeria

*Corresponding author: ayo_oseni@yahoo.com

\begin{abstract}
In recent times, interest in the study of engineering structures has been on the rise as a result of improvement in the tools used for operations such as, As-built mapping, deformation studies to modeling for navigation etc. There is a need to be able to model structure in such way that accurate needed information about positions of structures, features, points and dimensions can be easily extracted without having to pay physical visits to site to obtain measurement of the various components of structures.

In this project, the data acquisition system used is the terrestrial laser scanner, High Definition Surveying (HDS) equipment; the methodology employed is similar to Close Range Photogrammetry (CRP). CRP is a budding technique or field used for data acquisition in Geomatics. It is a subset of the general photogrammetry; it is often loosely tagged terrestrial photogrammetry. The terrestrial laser scanning technology is a data acquisition system similar to CRP in terms of deigning the positioning of instrument and targets, calibration, ground control point, speed of data acquisition, data processing (interior, relative and absolute orientation) and the accuracy obtainable. The aim of this project was to generate the threedimensional model of structures in the Faculty of Engineering, University of Lagos using High Definition Surveying, the Leica Scan Station 2 HDS equipment was used along with Cyclone software for data acquisition and processing.

The result was a $3 D$ view (of point clouds) of the structure that was studied, from which features were measured from the model generated and compared with physical measurement on site. The technology of the laser scanner proved to be quite useful and reliable in generating three dimensional models without compromising accuracy and precision. The generation of the $3 D$ models is the replica of reality of the structures with accurate dimensions and location.
\end{abstract}

Keywords - Point cloud, Scan station, Laser Scanning, High Density Scanner, Georeferencing.

\section{INTRODUCTION}

In any field of study, solutions to problems are developed based on the information acquired about the subject matter. The subject matter may involve tangible or intangible entities but, in engineering, the subject matter is usually tangible, and in this case, it is a physical structure. To obtain any relevant information about a structure, data has to be collected.

"Geomatics engineering is a modern discipline, which integrates acquisition, modeling, analysis, and management of spatially referenced data, i.e. data identified according to their locations. Based on the scientific framework of geodesy, it uses terrestrial, marine, airborne, and satellitebased sensors to acquire spatial and other data. It includes the process of transforming spatially referenced data from different sources into common information systems with well-defined accuracy characteristics." (http://en.wikipedia.org/wiki/Geomatics)

The branches of Geomatics Engineering include Hydrography (hydrogeomatics), Astrophysics, Geophysics, land surveying (Cadastral and Geodetic surveying), remote sensing, cartography, Geographic Information Systems (GIS), photogrammetry etc. During the last decade, the world of engineering surveying has seen enormous developments in the techniques for spatial data acquisition. 
This project attempt to explore one of the recent data acquisition systems which can be termed a fusion of 'remote sensing' techniques and 'close range photogrammetry' (CRP) methods.

Remote sensing is the acquisition of information about an object or phenomenon, without making physical contact with the object. This is possible with the aid of sensors which measure and record some properties (radiation) of the object. Remote sensing could be passive or active; passive when the sensor records natural emissions and reflection from the object and, active when the sensor itself sends a signal to the object and measures the reflected signal over a short space of time. The data acquisition system used in this project operates on the active remote sensing technique. It can also be likened to CRP with respect to the design of the instrument and target positioning, data processing (interior, relative and absolute orientation) and accuracy.

The Leica Scan Station2 High Definition Surveying (HDS) equipment was used along with Cyclone 7.0.3 for data acquisition and processing in this project. High Definition Surveying (HDS) or simply laser scanning is the collection of high-density spatial data sets relating to a structure/objects or land for use in asset and site development planning or dimensional control (http://www.starnetgeomatics.com/laser_scanning.php).

Terrestrial laser scanners acquire data in form of point clouds in 3 dimensions $\mathrm{x}, \mathrm{y}$ and $\mathrm{z}$, from every scene or station without the need for overlap. It provides the users with the possibilities of direct and automated 3D data capture. TLS employs an indirect ranging principle. The distance, or range from the sensor (a terrestrial laser scanner) to a point on the object surface is determined with high accuracy by measuring the time elapsed between the emission of a laser signal and detection of its portion backscattered from the surface (time-of-flight, TOF). TOF laser scanners employ the following techniques for measuring the travel time of a signal by utilizing different physical effects Wehr and Lohr 1999; Lange 2000).

3D data acquisition about terrestrial objects has been a source of continual research as new technologies keep coming up year after year. The most celebrated methods of simultaneous 3D data acquisition of multiple points and objects are still terrestrial laser scanning and CRP. The data obtained are processed on the computer.

\subsection{Statement of the Problem}

There is a need to be able to model structure in such way that accurate needed information about positions of features and points can be easily extracted without having to pay physical visits to site. A model that represents an accurate as built survey would effectively solve this problem. The risk involved in some engineering works especially with high rise structure sometimes can be so enormous. Development of models like this therefore becomes imperative in order to reduce risk to as low as reasonably practicable.

\subsection{Study Area}

The case study, Faculty of Engineering, University of Lagos, Akoka, Lagos, is situated on the main campus; directly opposite Senate car park and Main Auditorium. It was established in the 1964/65academic year with three departments namely Civil, Electrical and Mechanical Engineering.

The Sub Department constituted the core group of hybrid mathematicians and professional engineers who provided academic leadership in various areas of Engineering Analysis.

It was later to become the Department of Systems Engineering. Later in 1973, two other departments, Chemical Engineering and Surveying, were established.

Beginning from the 1982/83 session, the Faculty switched over to the present 5 -year programme characterized by the Unit Course System.

The faculty of Engineering has several buildings such as Engineering lecture theatre, New Julius Berger Engineering building, Deans office, Professors, Departmental offices, Laboratories, underground tunnel workshops and classroom blocks. It also boasts of a well laid out walk way and gardens. All of which form our study area (both the inside and outside).

\section{LITERATURE REVIEW}

\subsection{Laser Scanner Overview}

Laser scanners are able to conduct rapid and very dense surveys of a structure within an hour (Hirst and Roberts, 2005). The laser scanner can capture and record hundreds and thousands of angles and distances. The distance and angles recorded are transformed in to a dense point cloud of millions of $\mathrm{x}, \mathrm{y}, \mathrm{z}$ points that represent the object being scanned. Laser scanners record up wards of 50,000 points a 
second and the finished point cloud contain many millions of $\mathrm{x}, \mathrm{y}, \mathrm{z}$ points.

The point cloud is displayed in a software package such as Leica's Cyclone or Maptek's Vulcan but for the purpose of the project, the Cyclone 7.0.3 software was used. Many conventional survey software packages have been upgraded to have the ability to view or edit point clouds. The laser scanner works somewhat like an automated total station in that it can be force-centred over a mark and back-sighted to a target. Unlike a total station, where the operator selects all the points for measuring and recording, the laser scanner uses a time of flight measurement or pulsed diode laser for measuring the distance of the transmitted laser and an internal angle recorder to measure the angle that the laser transmitted and the angle the laser receives. The laser scanner has an automated system that programs the scanner to rotate $360^{\circ}$ in the horizontal plane and up to $270^{\circ}$ in the vertical plane. Different brands of laser scanners have different fields of view (Lichti et al, 1999). The laser that is transmitted hits the surface of the structure being scanned and reflects back to the laser scanner. The laser scanner measures the intensity of the return beam. This intensity is dependent on the reflectivity of the surface. A high reflectivity surface such as a white smooth wall, will give good results while a dark or wet surface will have the low reflectivity. Most laser scanners are able to take a 360 degree panoramic photo of the area being scanned and this photo can provide real colour to the point cloud. This is done by providing coordinates of the digital photo and allows easy interpretation of the point cloud (Bornaz et al, 2004). The spot size of the transmitted laser is an important factor to consider when discussing laser scanning. When a laser is transmitted the laser spot size will increase in size the further the laser has to travel to meet its reflective surface. In the instance of Leica's new HDS6000 the spot size is $8 \mathrm{~mm}$ at 25 metres and $14 \mathrm{~mm}$ at 50 metres. Edges of structures will also affect the transmitted laser beam. When only part of the laser beam reflects back off a surface, the other part of the laser will continue until it hits a reflective object and reflects back to the scanner. These edge points will be incorrect. The best way to eliminate this problem is to conduct 2 set ups of the laser scanner from different viewpoints of the edge. This principle is what was applied in the scanning process whereby we created a region of overlap between two scan stations.

\subsection{Application of Terrestrial Laser scanning approach to 3D modeling}

Due to its fast and accurate ability to scan objects and surfaces, the laser scanner is being utilized in many industries including mining and archeology. The ability of the laser scanner to pick up points without having to have an assistant place a target on the surface or object means that it is perfectly suited to survey dangerous features like busy highways (Chow, 1999) and landslide surveys (Bitelli et al, 2004). Bitelli et al (2004) used laser scanning to monitor a land slip site in Northern Italy, usually this type of work would be done by aerial Photogrammetry methods. The traditional method of airborne surveying was compared to terrestrial laser scanning of the land slip site, which was 40,000 square meters in size. The authors found that the laser scanner provided a fast, accurate and relatively cheap way to monitor mid-size landslide areas compared to airborne survey techniques.

Chow (2004) used a Leica HDS3000 laser scanner to pick up surfaces on high-speed highways in Hong Kong . Using traditional surveying methods, this would have involved the closure of roads and would have been costly. It would have been unlikely to be approved by the road transport authority of the Hong Kong Police. Laser scanning allowed the safe and accurate, non-contact survey of the highway surfaces and features without the closure of roads and the risk to survey personnel. Compared to the traditional method of reflector less measurements to features, and the time taken due to false measurements caused by traffic, the laser scanner produced sub-centimeter accuracy. A ground model was formed and a 1:500 scale topographical map of the area was produced.

Schmid et al (2005), in the logging areas in south West Germany used the laser scanning to monitor soil erosion, a scan of the area was done before and immediately after logging. Another scan was done a year after logging. The model generated for the area showed the effects caused by the logging equipment on the soil. The volume of soil removed was afterwards calculated by analysis of the surface models.

Chow (2007) employed the use of this technology in the capture of survey data in different highway working environments. He highlighted the experience gained in the surveying of ground profile of high-speed roads where traditional survey is greatly difficult to be done without road closure, the steep roadside slope and the headroom clearance 
of high voltage overhanging cables across the expressway. The strengths, limitations, and other possible applications of using the terrestrial laser scanner in highway engineering surveys were also addressed.

Behr et al (1999) used a laser scanner to monitor the deformation of a lock that connected a shipping channel to the North Sea near Amsterdam. The project was aimed at monitoring deformation caused by changes in water level. Two scans of the lock were done from a fixed position. Because the scans were both taken from the same point a point analysis was done. The results showed that there was movement in the lock

Corrado Alvaro1 et al (2009), carried an Architectural analysis and 3D reconstruction of Leopoli-Cencelle in Italy. Laser scanning, GPS and orthophotography data were integrated for the study of the medieval church of Leopoli Cencelle. Its main purpose was to present a $3 \mathrm{~d}$ model and the methodological approaches used in the archaeological analysis. The site of Leopoli - Cencelle is in the area of Tarquinia (province of Viterbo), approximately $70 \mathrm{~km}$ to the north of Rome.

\section{RESEARCH METHOD}

Terrestrial laser scanning technique used in this project bears some similarities to some photogrammetric principles. The similarities include registration of scan to scan, which can be likened to relative orientation; Georeferencing by registration, which is also similar to absolute orientation.

The instruments used in this project are classified into hardware and software. The different hardware used are; from control survey was done by GPS, target coordination by total station e.t.c. Leica Promark 3 (dual antenna) GPS and accessories, Leica TS06 total station and accessories, Leica Scan Station 2 HDS and accessories. Various software products were used for data acquisition, data processing, visualization, analyses and interpretation which include Cyclone 7.0.3, Leica Geo-Office, Microsoft Access 2007 and Microsoft Excel 2007.

A Reconnaissance survey of the area of study was carried out, the design stage was done in the office, drawing from the experience of the field reconnaissance survey and the data acquired from the office reconnaissance survey. Identified spots from the field were marked on the architectural plan and a network was created of points were created. Every prospective station was designed to accommodate four target points in four different directions, so as to have good alignments for scan world to scan world registration (relative orientation)

The instrument stations were marked on the ground by a 'point edge nail' embedded in a triangular mark on the ground each station was also given specific names or code. The first station occupied was named "station1", and its corresponding targets were coded as 'tgt1', 'tgt2', 'tgt3' and 'tgt4'.

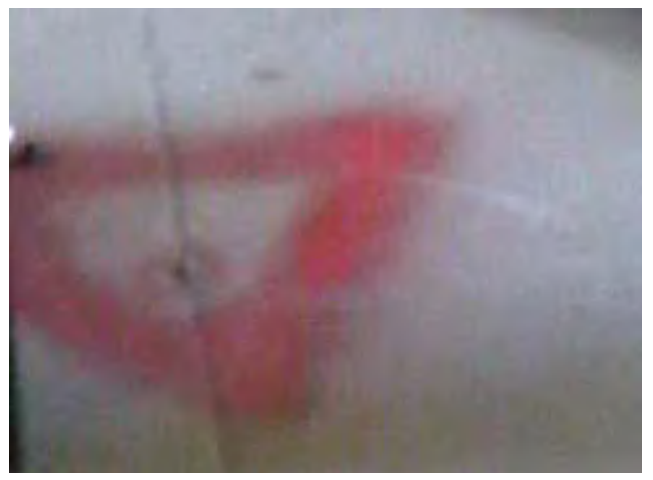

Fig.3.1: Station marking for one of the stations

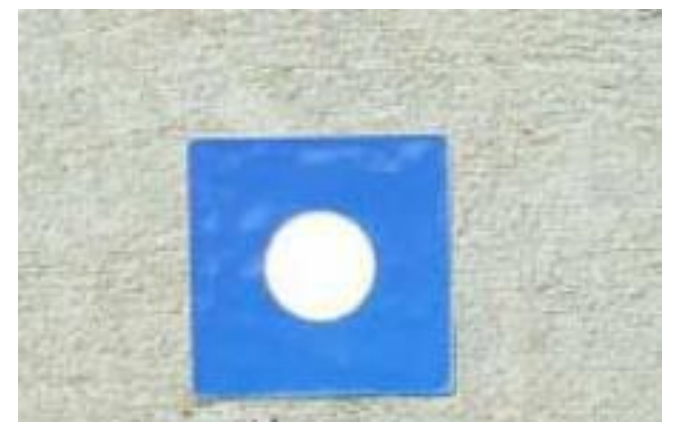

Fig.3.2: Target and target description

The survey can be classified into three different classes namely; Laser scanning, Control survey, Specific point survey. The laser scanning was done using the Leica Scan Station 2 (HDS 3000). The Leica Scan Station 2 is also used in a step by step approach. Set up, configuration, settings, probing, 3D image acquisition, target acquisition, point cloud acquisition. 


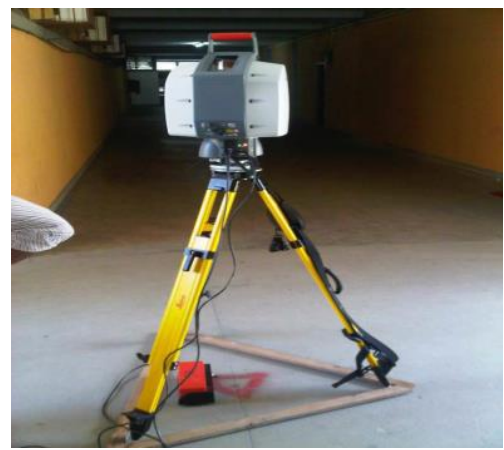

Fig.3.3: Showing the set up of the instrument, after connecting the cable

The scanner was configured by adding a new scanner on the window. It was named Unilag and the IP address (10.1.204.55) on the instrument was entered.

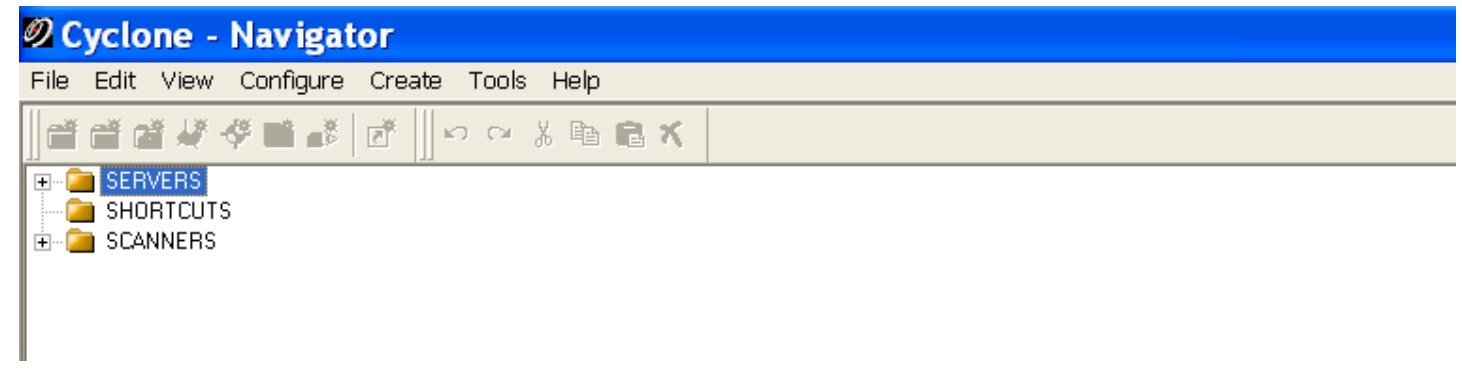

Fig.3.4: Showing the default look of the cyclone 7.0.3 environment

Other configurations that were done were for the 'server' and the 'database' used for the project. The server was added as 'USER (Unshared)' and the database was named '3D modelling'.

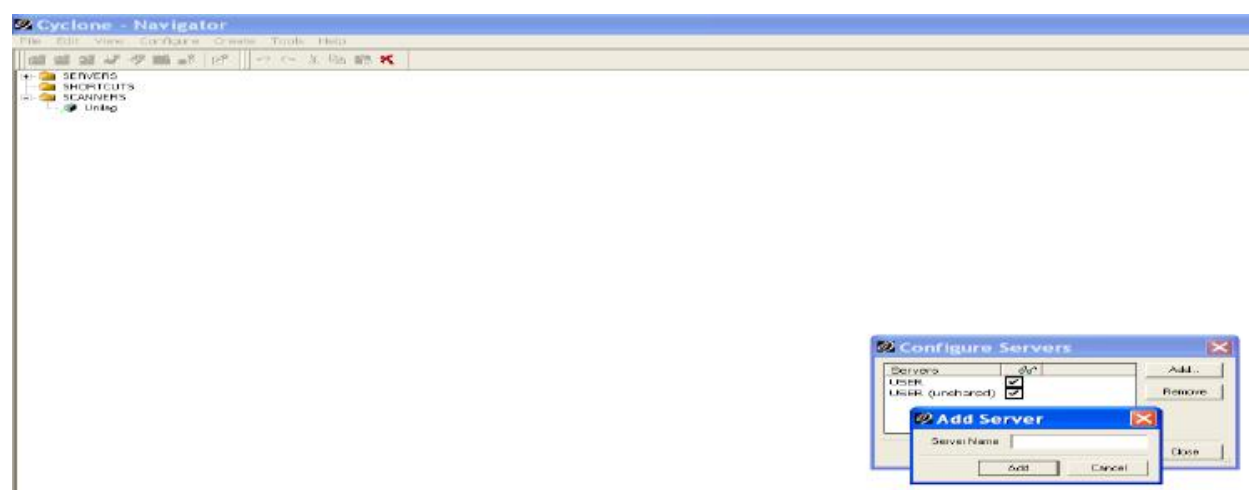

Fig.3.5: Showing configuration stage for server after configuring the scanner 


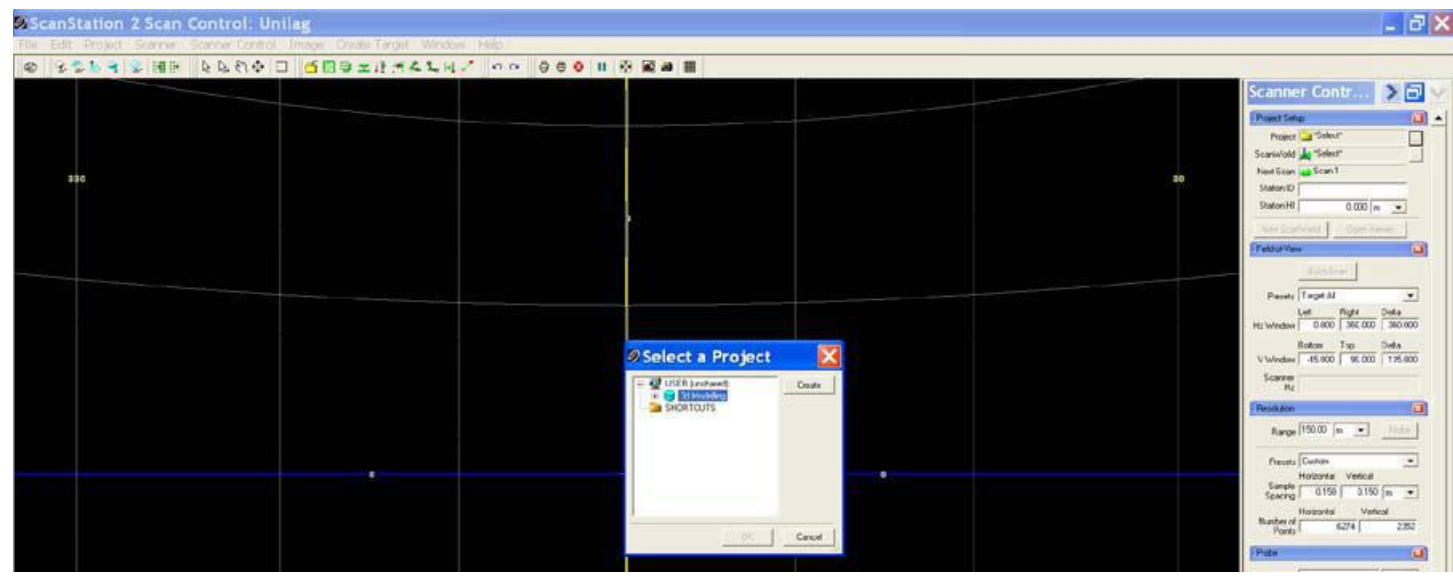

Fig.3.6: Creation of a project into the configured database via the scan control window

Once created, the workspace automatically opened up with a scanworld name which was edited and saved as 'station1

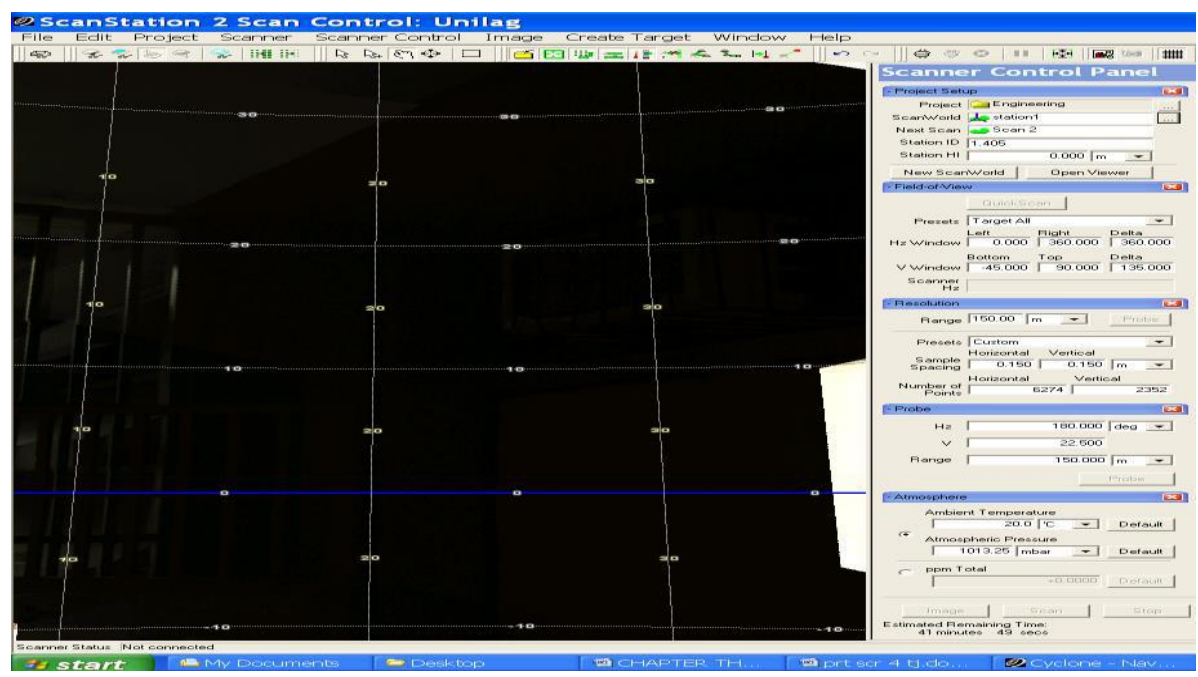

Fig.3.7: Showing the scan control window

For every station occupied, the 3D image was taken, spanning the field of view, it was done by clicking 'get image' on the image menu from the scan control window. This enabled us to see the features around the structure, especially the targets and where they fell in the scan control window. Knowing where the targets are on the scan control window makes it easier for anyone to acquire the scan for the targets. 


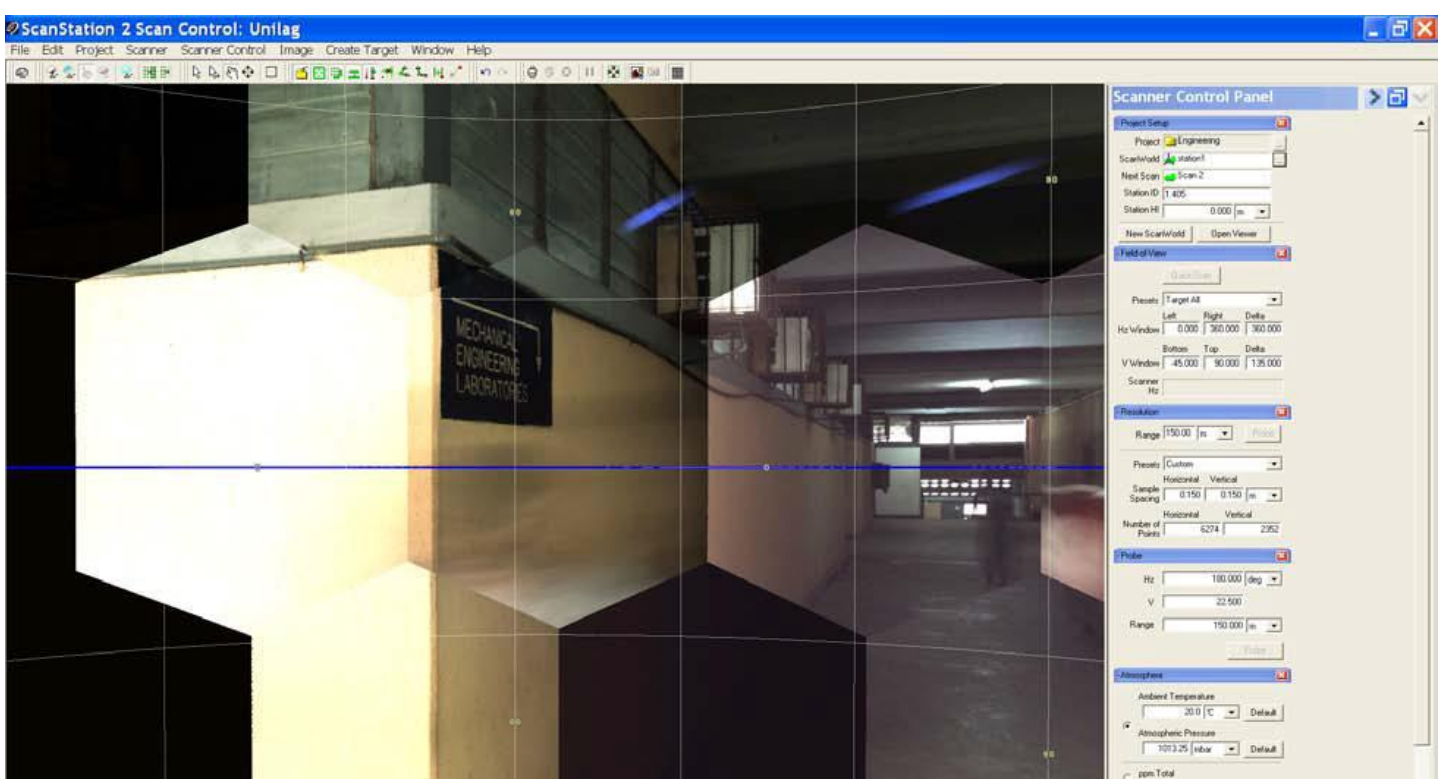

Fig.3.8: Acquiring the 3D image (from the scan control window).

Targets were acquired by first defining a fence around where they were shown in the image acquired. The fence was to define a smaller field of view for the scanner to search for them, it made target acquisition easier and faster. After defining the fence, the targets were acquired using the scanner control menu and clicking on 'Acquire targets'. As it was with the instrument itself, the target height was noted and imputed in the target listing, with each target given its own target ID.

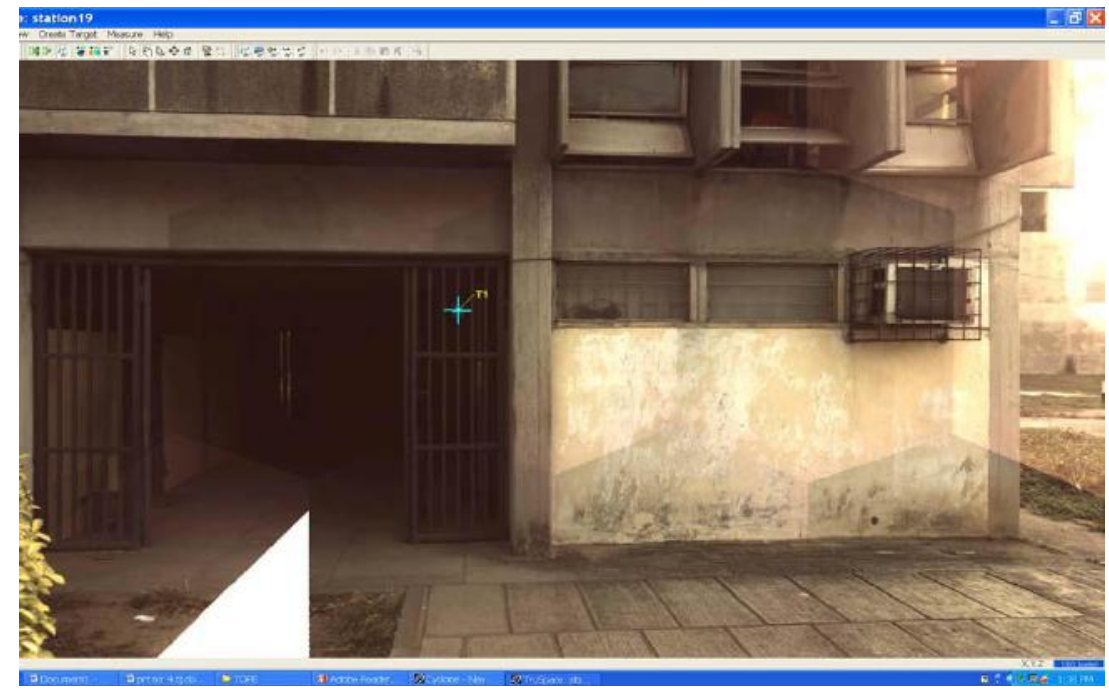

Fig.3.9: Acquired targets from the $3 d$ picture taken from another station

To acquire the point clouds, the scan button on the scan control window or navigating through the scan control menu on the menu bar. We used either as soothing to the person acquiring the scan at that specific station. 


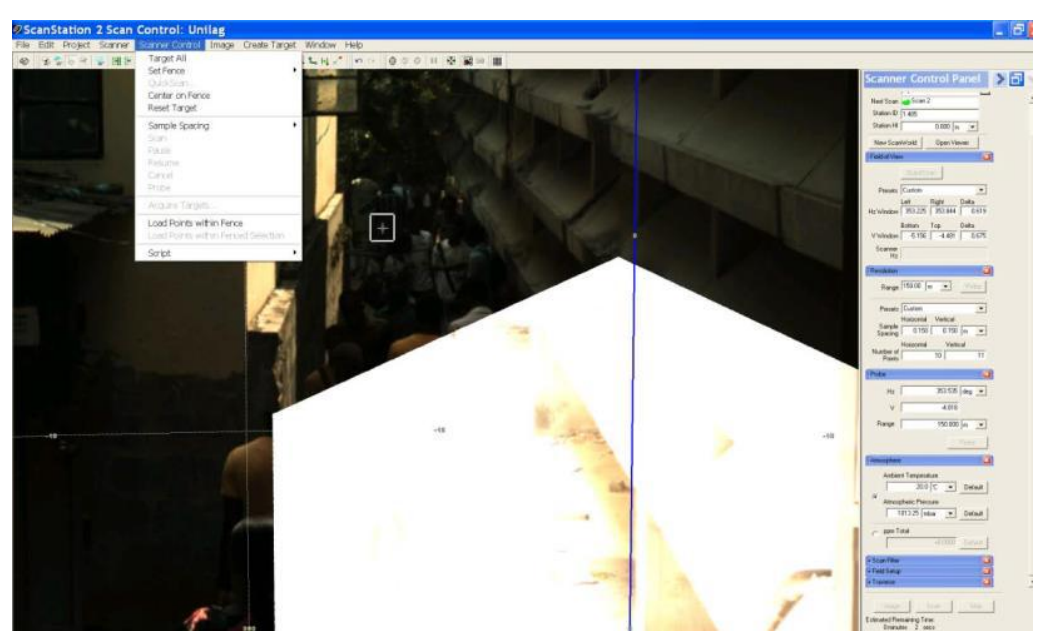

Fig.3.10: Process of initiating the scan

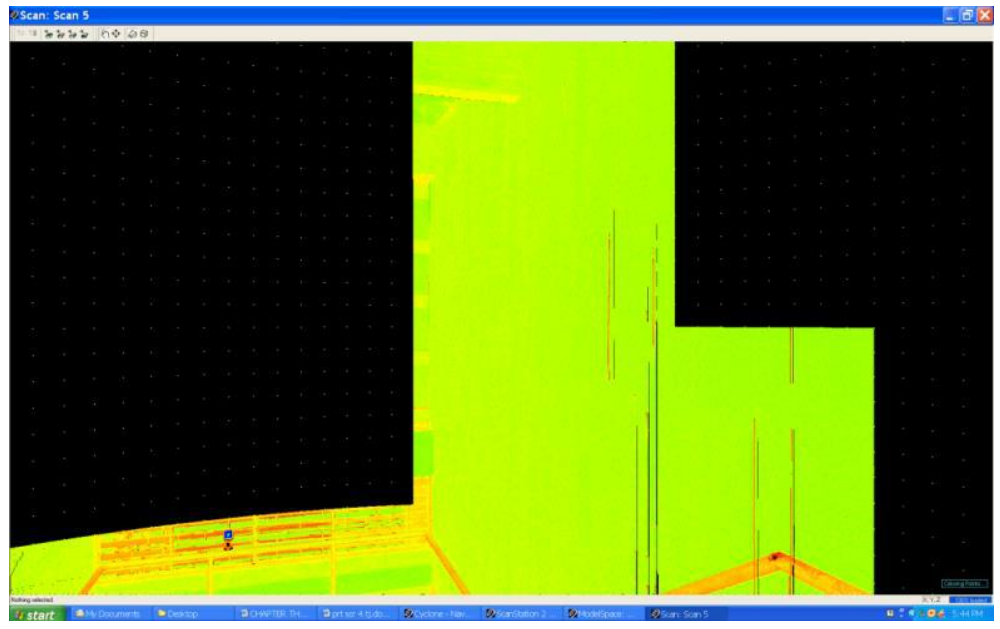

Fig.3.11: Point clouds loading during scanning 


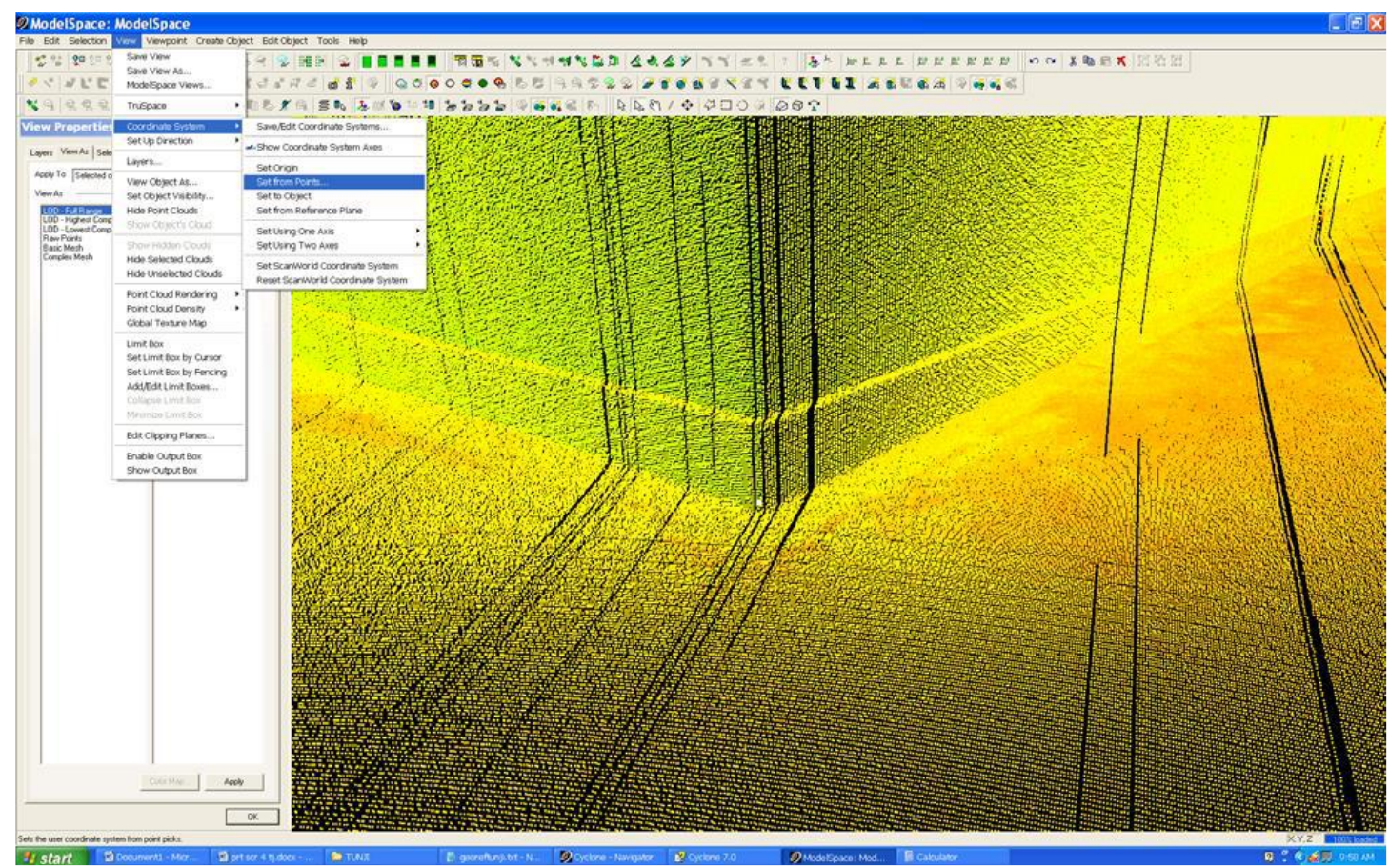

Fig.3.12: Accessing the coordinate system of the current scanworld for the transformation.

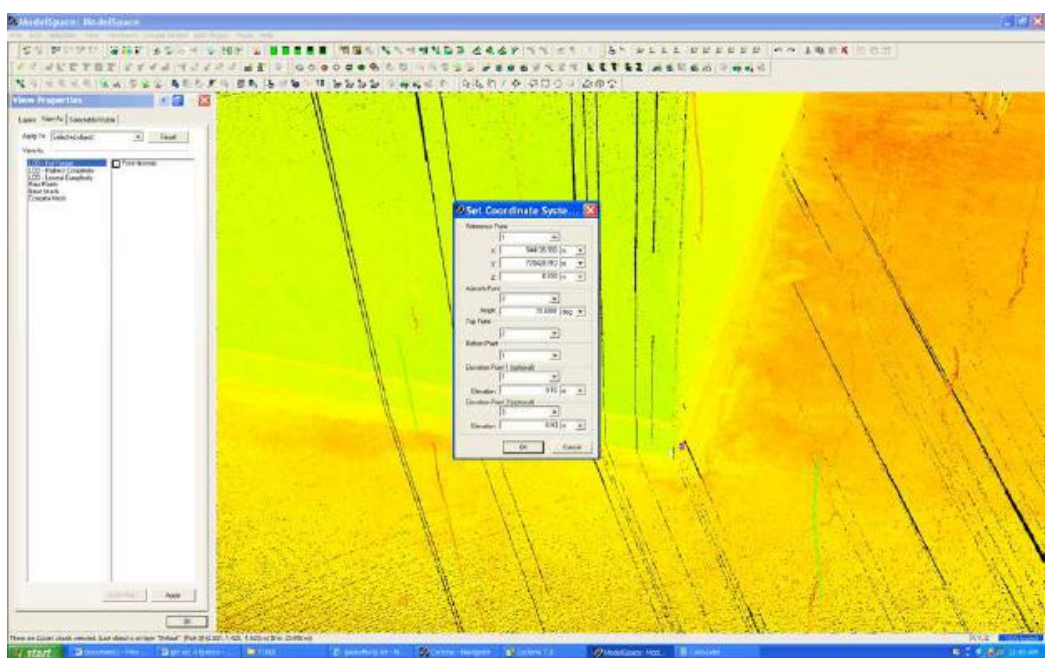

Fig.3.13: Fixing the required parameters for the three points in chosen.

Modeling in the cyclone environment is also refered to as 'meshing'. The meshing tool that defines the solid/model that we desire is called complex meshing. However, the complex meshing tool became inactive when all the point clouds were selected. As such all the point clouds in ScanWorld [Surveying and Geo Office] could not be used to make the model. Alternatively, point clouds were selected generally across the scanworld and the space was viewed as a complex mesh 


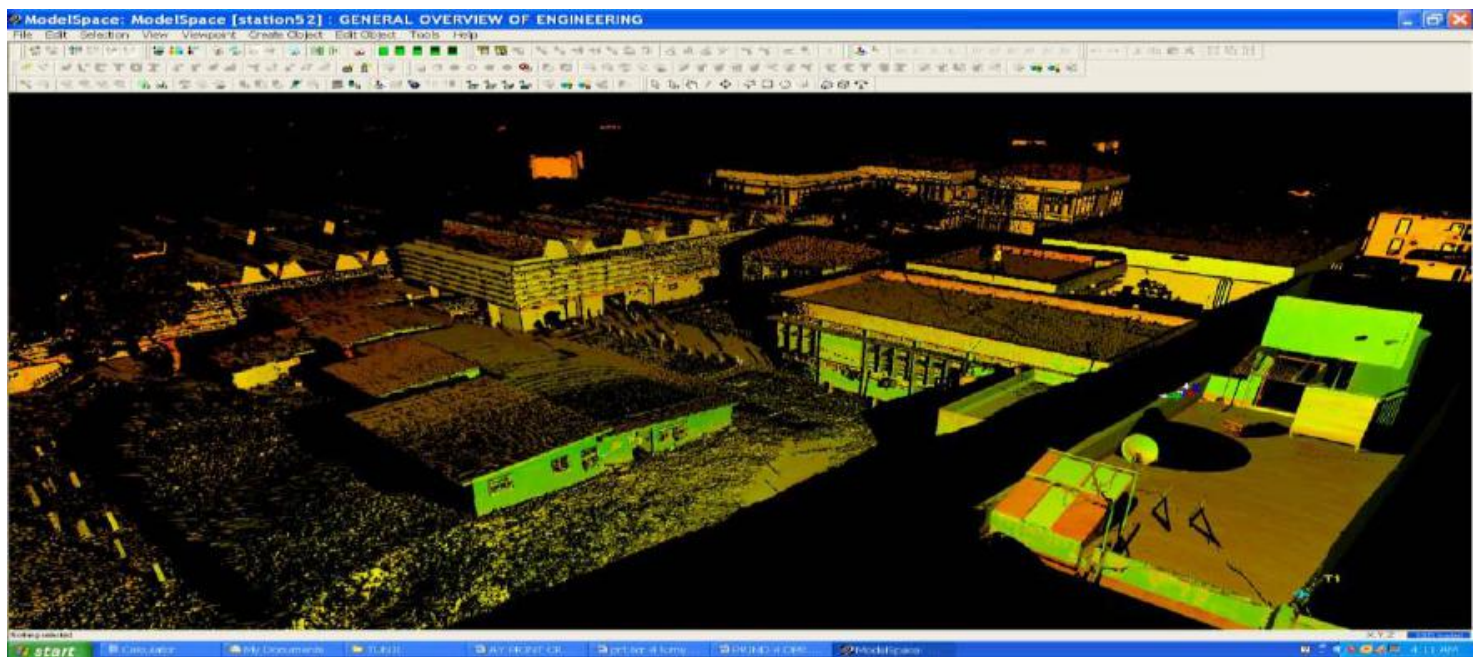

Fig.3.14: The Mesh Aerial View of the faculty of engineering from energy and conservation centre

A 'fly through' was done on the modelled structure by panning and zooming through in point cloud or model viewing mode. The animation was done by creating a layer for animation, inserting cameras, connecting cameras with paths, editing animation parameters and saving the animated view as a video file.

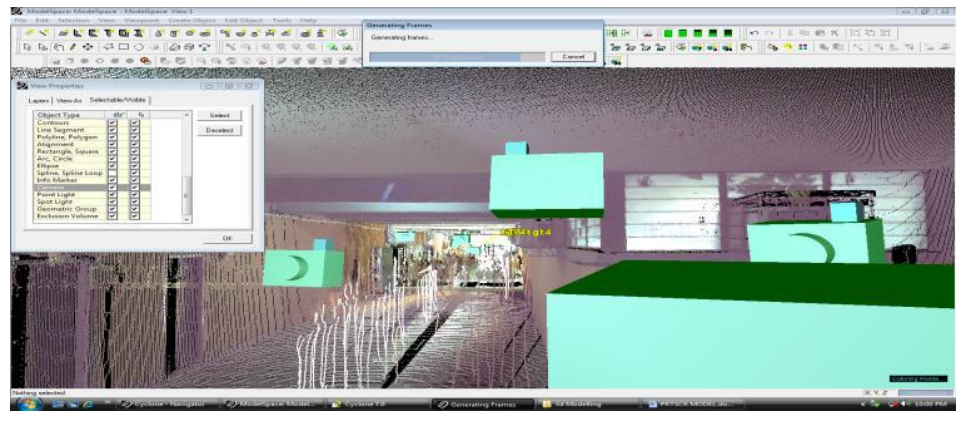

Fig.3.15: Camera position and positioning during animation building

\section{FINDINGS AND DISCUSSION OF RESULTS}

From the control and target surveys, coordinates were obtained for about one hundred points in and around the survey area. However only the coordinates relating to Station 1 and Station 2 are shown.

Table 4.1. Showing the coordinates established from the GPS control survey.

\begin{tabular}{|l|l|l|l|l|}
\hline Easting & Northing & Elevation & Point Id & Remark \\
\hline 544197.299 & 720454.173 & 6.779 & L001 & Control \\
\hline 544231.361 & 720437.129 & 7 & L002 & Control \\
\hline
\end{tabular}

Contiguous and overlapping scan worlds were registered together to form a single and seamless scanworld. The coordinate system of individual ScanWorlds are transformed into a common coordinate system; this is similar to 'relative orientation' in photogrammetry. 


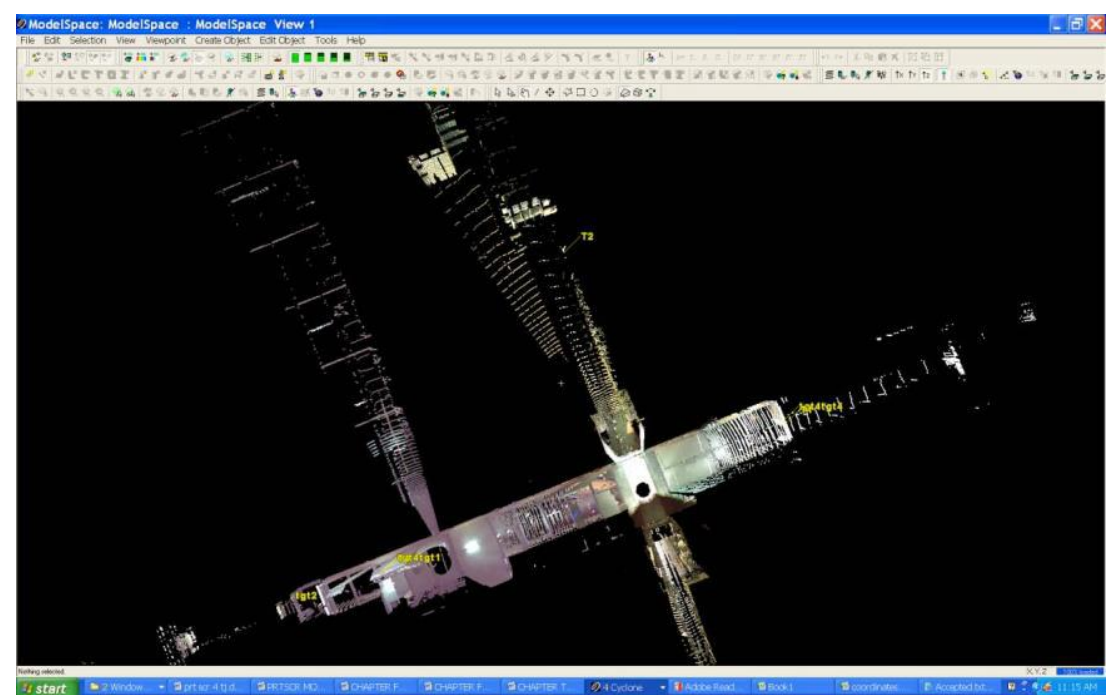

Fig.4.1: Two stations from a single scan world, showing the registered scan worlds.

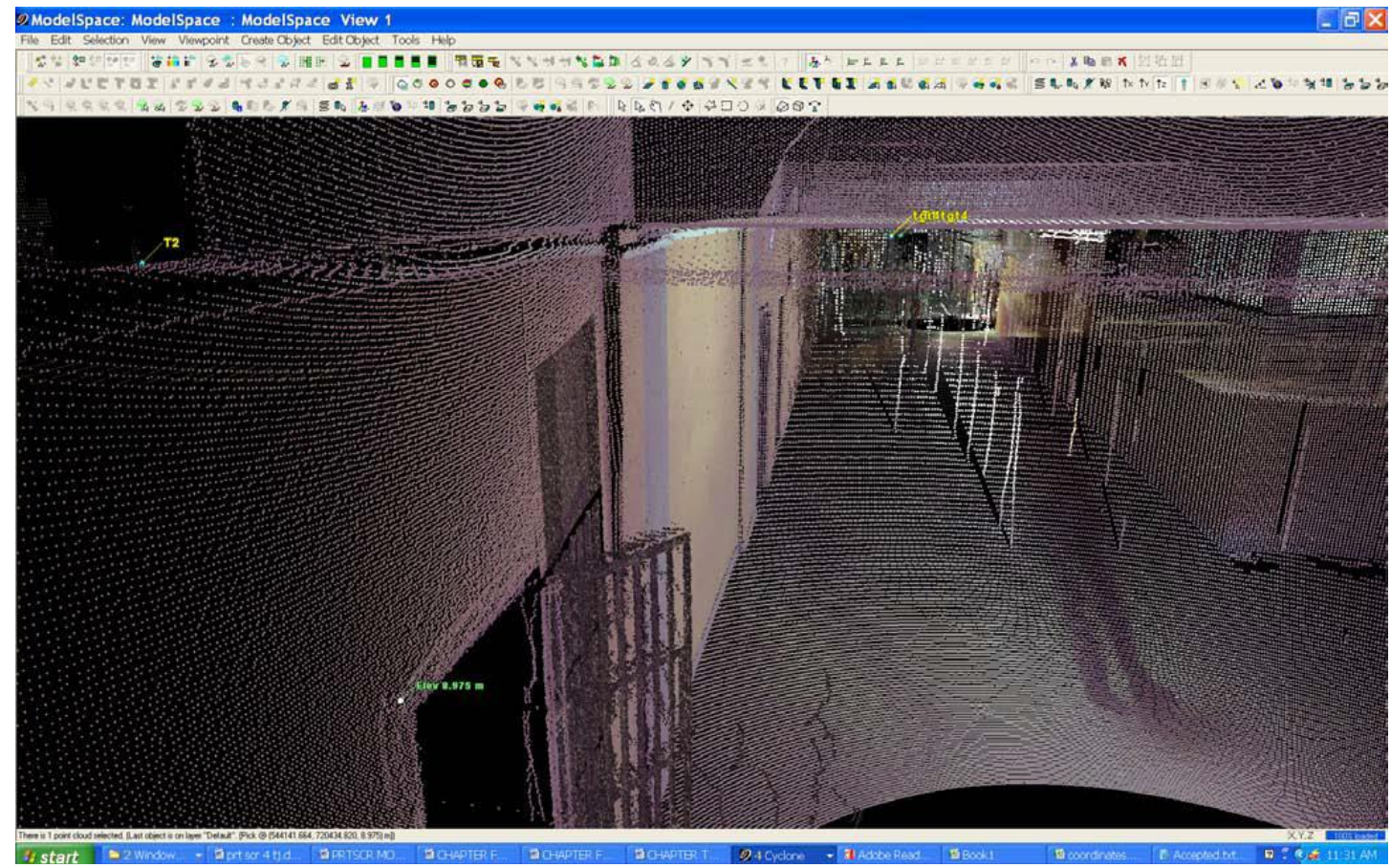

Fig.4.2: Registered scanworld in real life coordinates.

\subsection{ANALYSES}

The registration process from scanworld to scanworld can actually be done in various ways. These are Target constraint alone, Cloud constraint alone or hybrid method. Cloud constraint alone was adopted for this project. 


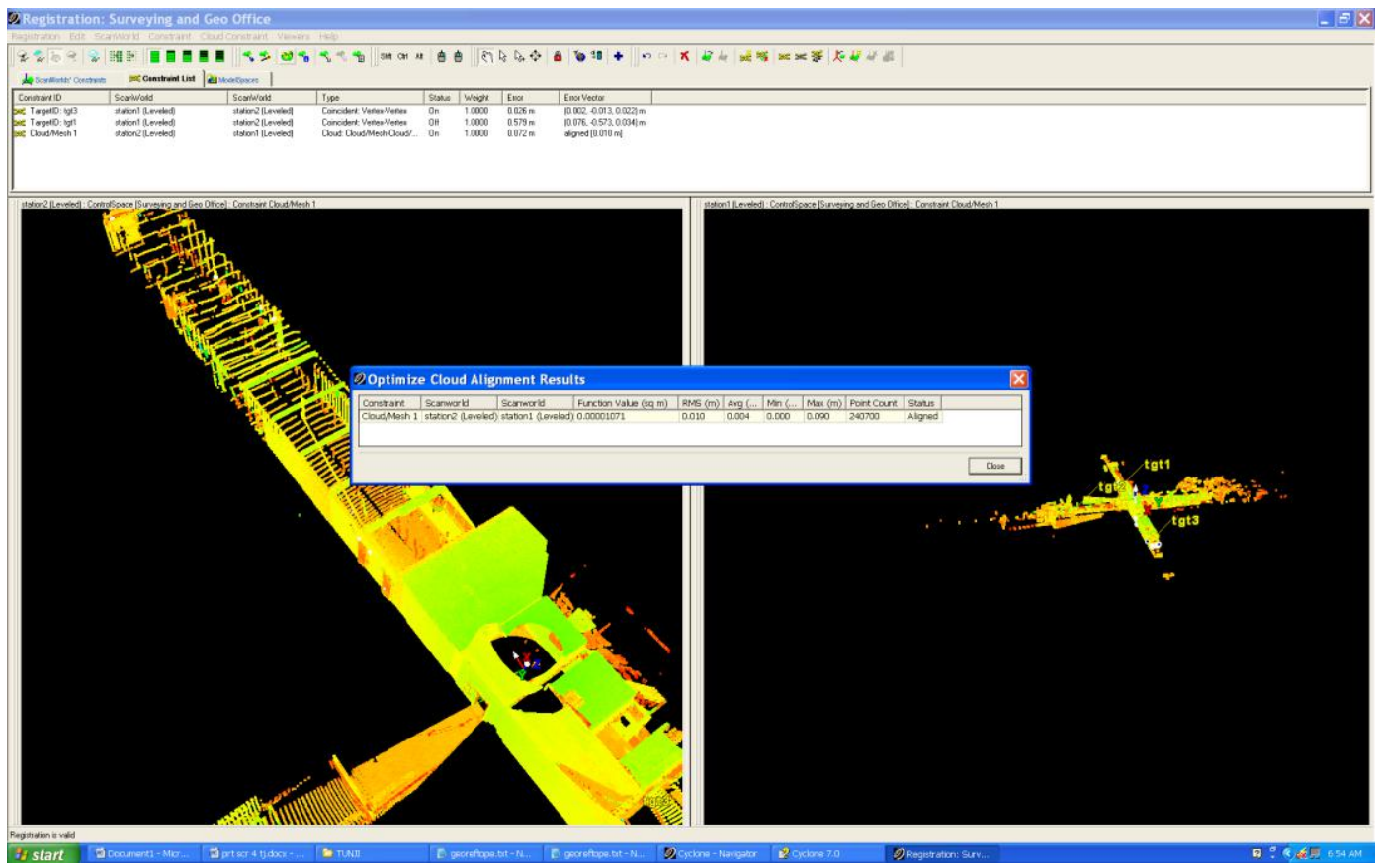

Fig.4.3: Cloud optimization result.

During the coordinate transformation stage, only three points were used to re-orient the scanworld into real life coordinate system ( absolute orientation). The points used were tagged Georef_8, Georef_7 and Georef_12 as points 1, 2 and 3 respectively. However, other points were also bisected with the total station on the field. All the points that were acquired on the field using the total station were also converted and imported into cyclone as targets.

Checking was done in two ways. Firstly, points of known coordinates on the structure were picked in the scanworld, and the coordinates obtained from cyclone was checked against the corresponding downloaded sets of coordinates from the total station.

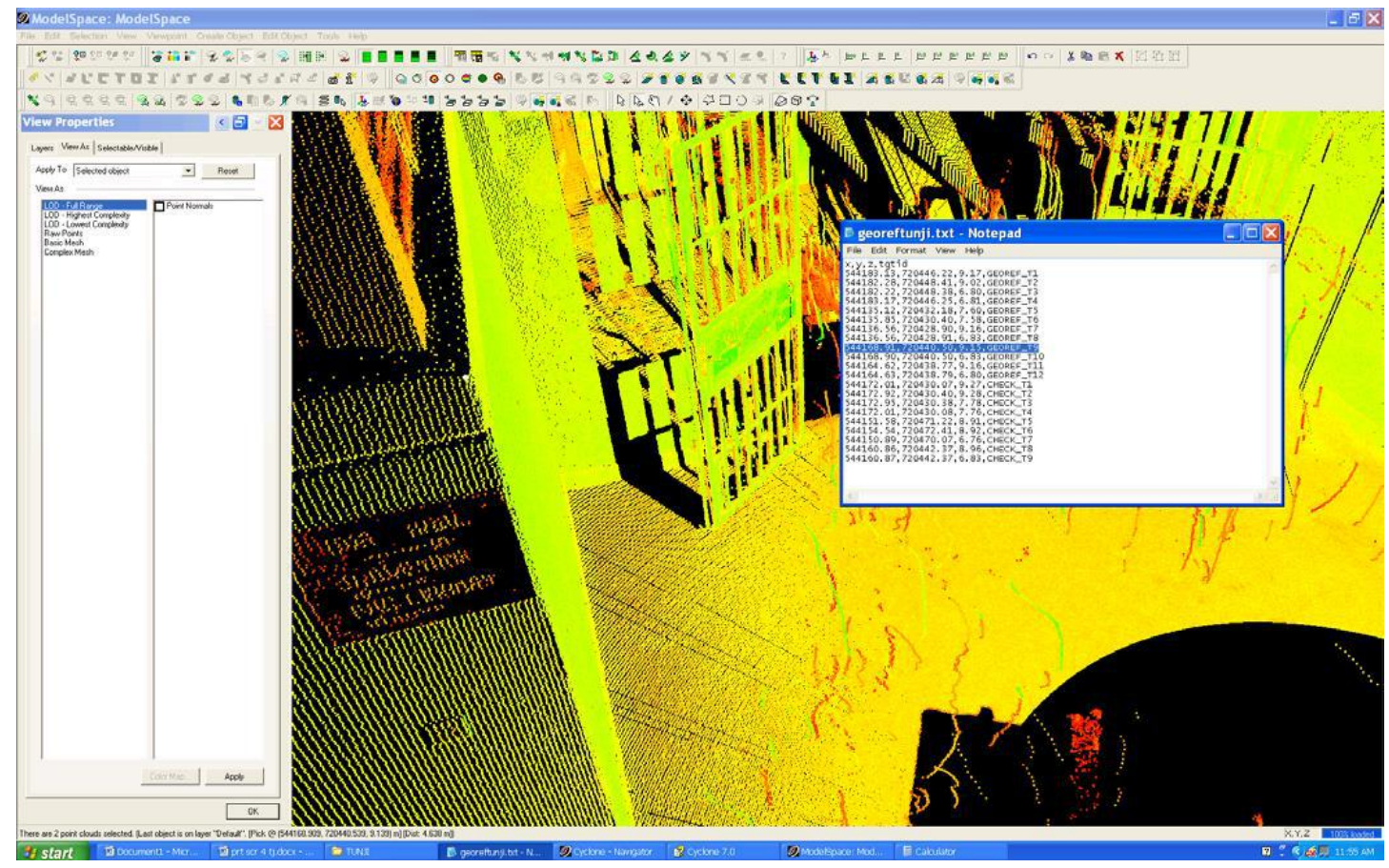

Fig.4.4: Picked point on the scan against the corresponding coordinated point on ground 
From Figure 4.4 above, the picked point on the scan is having coordinates showing on the lower left corner of the window and the total station coordinate is also shown as an overlay. The table below shows the comparative coordinates for point ID GEOREF_T9.

Table 4.2: Comparative coordinates for point ID GEOREF_T9.

\begin{tabular}{|l|l|l|l|l|l|l|l|l|}
\hline $\begin{array}{l}\text { Point } \\
\text { Cloud } \\
\text { Easting }(\mathrm{m})\end{array}$ & $\begin{array}{l}\text { Total } \\
\text { Station } \\
\text { Easting } \\
(\mathrm{m})\end{array}$ & $\begin{array}{l}\text { Difference } \\
\text { in Easting } \\
(\mathrm{m})\end{array}$ & $\begin{array}{l}\text { Point } \\
\text { Cloud } \\
\text { Northings } \\
(\mathrm{m})\end{array}$ & $\begin{array}{l}\text { Total } \\
\text { Station } \\
\text { Northings } \\
(\mathrm{m})\end{array}$ & $\begin{array}{l}\text { Difference } \\
\text { in } \\
\text { Northings } \\
(\mathrm{m})\end{array}$ & $\begin{array}{l}\text { Point } \\
\text { Cloud } \\
\text { Height } \\
(\mathrm{m})\end{array}$ & $\begin{array}{l}\text { Total } \\
\text { Station } \\
\text { Reduced } \\
\text { Level } \\
(\mathrm{m})\end{array}$ & $\begin{array}{l}\text { Difference } \\
\text { in Height } \\
(\mathrm{m})\end{array}$ \\
\hline 544168.909 & 544168.91 & 0.001 & 720440.539 & 720440.50 & 0.039 & 9.139 & 9.15 & 0.011 \\
\hline
\end{tabular}

The imported 'targets' (i.e. field coordinates) was overlaid on the point clouds in the scan; from which approximate description or label was given to specific point clouds. Some measurements were taken with the linen tape and checked with the ones obtained in the scanworld. Two of such points are tabulated below;

Table 4.3: Measurement comparison

\begin{tabular}{|l|l|l|}
\hline Scanworld Measurement & Tape measurement & Station description \\
\hline $4.816 \mathrm{~m}$ & $4.82 \mathrm{~m}$ & Width of corridor \\
\hline $0.960 \mathrm{~m}$ & $0.98 \mathrm{~m}$ & $\begin{array}{l}\text { Width of entrance to } \\
\text { Departmental office }\end{array}$ \\
\hline
\end{tabular}

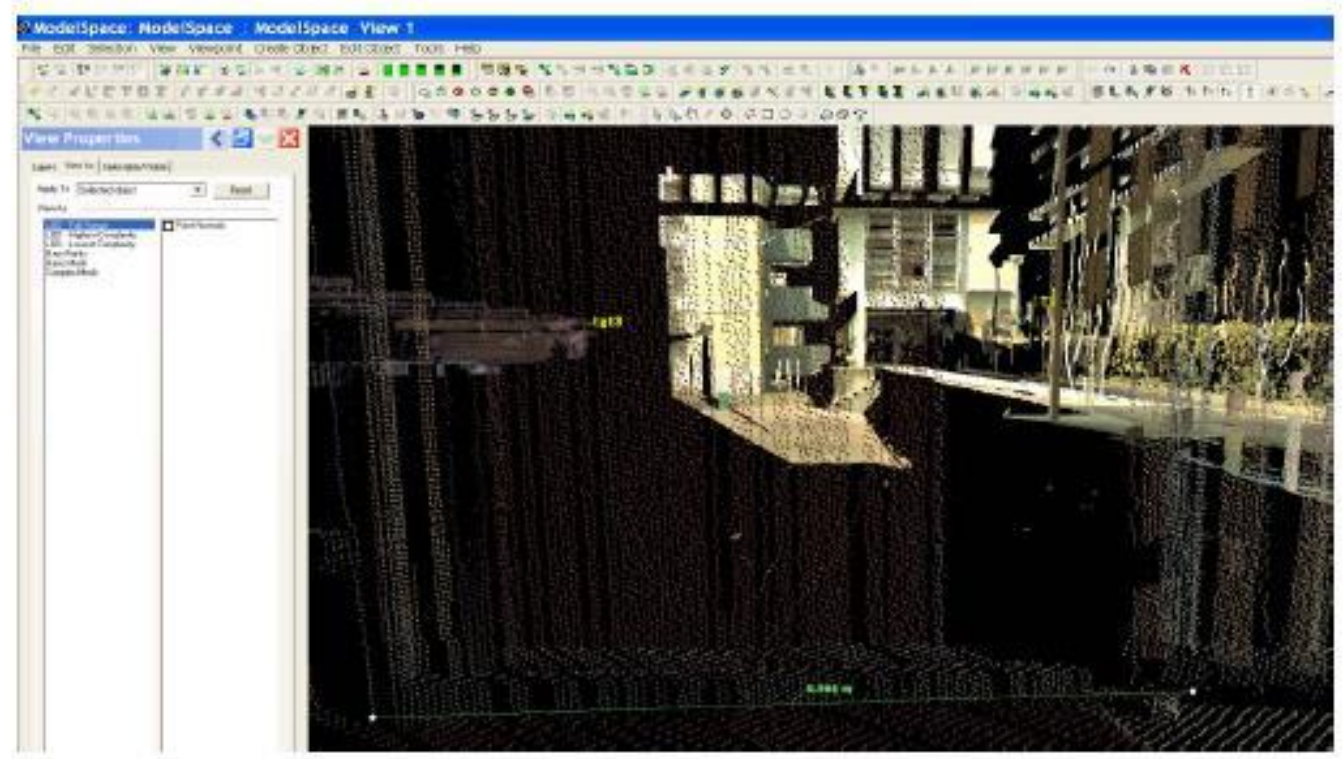

Fig.4.5: Showing the measured distance in the scanworld

Other measurements were taken from the point clouds to query distances and heights. As shown in the figure below; 


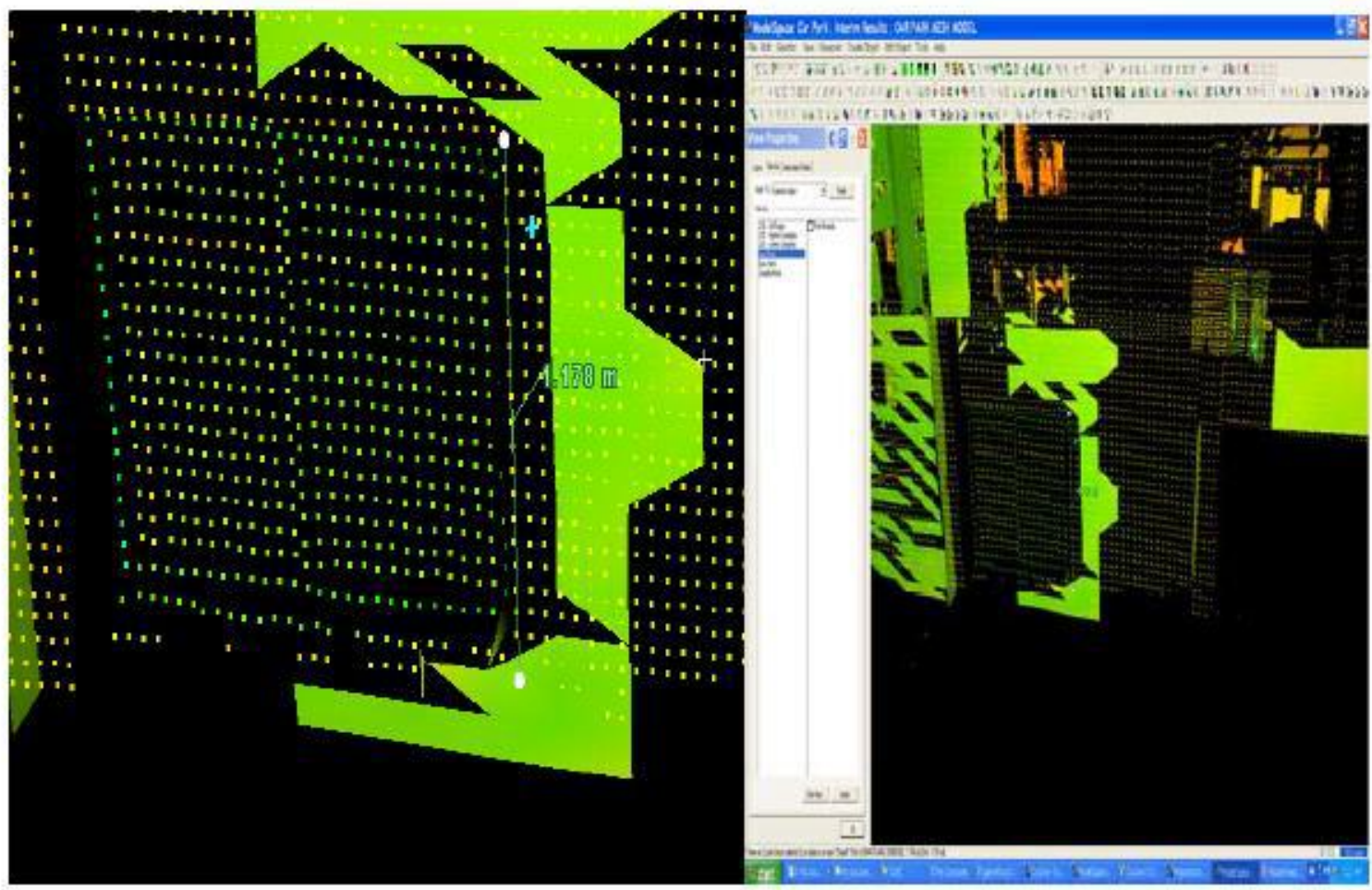

Fig.4.6: Image showing measurement of sign post taken

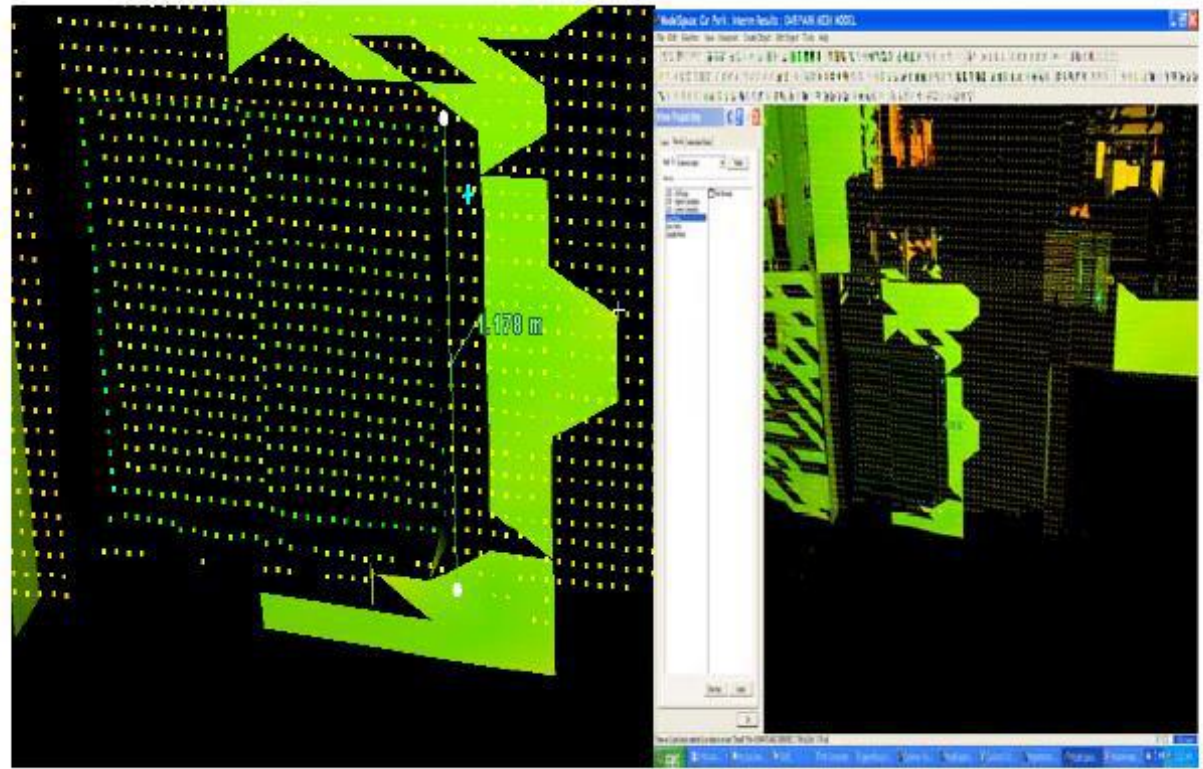

Fig.4.7: Image showing measurement of window side 
Table 4.4. Showing observed and extracted length of check features

\begin{tabular}{|l|l|l|}
\hline Scan station Measurement & Tape measurement & Site description \\
\hline $0.219 \mathrm{~m}$ & $0.217 \mathrm{~m}$ & Breadth of sign post \\
\hline $1.178 \mathrm{~m}$ & $1.165 \mathrm{~m}$ & Length of porters window \\
\hline
\end{tabular}

From observed data the error for the features can be calculated as;

$\Delta \mathrm{L}=\mathrm{L} 1-\mathrm{L} 2$ where $\mathrm{L} 1, \mathrm{~L} 2$ are measured length values. Therefore,

$0.219-0.217=0.002$ (Sign Post)

$1.178-1.165=0.011$ (Porter's Window)

Average of errors : $(0.002+0.0011) / 2=0.0065 \mathrm{~m}$

Net error is about $0.006 \mathrm{~m}$. This error may have been due to the scan interval specified.

\section{CONCLUSION}

It is safe to conclude that the project met its set out objectives. The generation of a three-dimensional model of the Engineering faculty using HDS was actually achieved and an added task of a walk-through simulation was added. The technology of the laser scanner was proven to be quite useful and reliable in generating three dimensional models without compromising accuracy and precision.

The generation of its three dimensions is reality based which makes the model generated, look as close as possible to physical realities. It was possible to make direct measurement to features to millimeter accuracy if desired from these models. The shapes and geometries of observed features were observed not be altered significantly except in places where obstructions existed. However, these obstructions are removable using noise clean ups. The laser technology provided the advantage of night observation- a feature not available to many other approaches. Quite a number of our scans were acquired at night. Some of the finest models generated were from scans acquired at night.

\section{REFERENCES}

[1] Alba M, Fregonese L, Prandi F, Scaioni M and Valgoi P (2005). Structural Monitoring Of A Large Dam By Terrestrial Laser Scanning, Close Range Sensing: Anaylsis and Applications, Commision 5,Viewed 11 March 2008, < http://www.isprs.org/commission5/proceedings06/paper/12 71_Dresden06.pdf.
[2] Bae K and Lichti D (2008). On-Site Self-Calibration Using Planar Features for Terrestrial Laser Scanners, Viewed 12 April 2008, www.spatial.curtin.edu.au.

[3] Baker A, Bannister A and Raymond S (1998). Surveying, 7th Edition, Longman Publishing, London.

[4] Balzani, M., Pellegrinelli, A., Perfetti, N and Uccelli, F (2001): A terrestrial 3D laser scanner: Accuracy tests. Proc. 18th Int. Symp. CIPA 2001, pp. 445-453.

[5] Behr J.A, Kenneth, Hudnut K.W and King N.E (1999). Monitoring Structural Deformation at Pacoima Dam California Using Continuous GPS, Seismological Reasearch Letters, Vol. 69, Issue No. 4, pp299-308, Viewed 7 April 2008, http://pasadena.wr.usgs.gov/office/hudnut/SRL/.

[6] Bitelli G, Dubbini M and Zanutta A (2008). Terrestrial Laser Scanning and Digital Photogrammetry Techniques to Monitor Landslide Bodies, Viewed 8 April 2008, http://www.cartesia.org

[7] Boehler W and Marbs A (2004). Investigating Laser Scanner Accuracy, Viewed 5 April 2004, www.leica-geosystems.com.

[8] Jacobs G (2008) . 3D Scanning: Getting Easier, Part 2// Professional Surveyor Magazine, 2008.

[9] Bornaz L and Rinaudo F (2005). Terrestrial Laser Scanner Data Processing, Close Range Sensing: Analysis and applications, Commission 5, Viewed 3 April 2008, http://www.isprs.org/istanbul2004/comm5/papers/608.pdf.

[10] Chow K (2007). Engineering Survey Applications of Terrestrial Laser Scanner in Highways Department of the Government of Hong Kong Special Administration Region (HKSAR), Commission 6 - Engineering Surveys, FIG Working Week 2007 / TS 6F - Terrestrial Laser Scanning I [7TS6F], www.fig.net.

[11] Jaszczak, P. J. (2006). Terrestrial Laser Scanning for landslides deformation monitoring. 
[12] Kager, H., Rottensteiner, F., Kerschner, M., Stadler, P., 2002. ORPHEUS 3.2.1 User Manual.

[13] Lange R (2000). 3D Time-of-Flight Distance Measurement with Custom Solid-State Image Sensors in CMOS-CCD Technology. A dissertation submitted to the Department of Electrical Engineering and Computer Science at University of Siegen (Germany) for the degree of Doctor of Technical Sciences. dokserv?idn=960293825\&dok_var=d1\&do

[14] Leica Geosystems, www.leicageosystems.com

[15] Leica HDS6000 (2008), A new generation of ultra-high speed laser scanner, 2008, Product brochure, www.leicageosystems.com

[16] Lichti D.D, Stewart M.P, Tsakiri M, A. J. Snow A.J (1999). Benchmark Tests on a Three-dimensional Laser Scanning System, www.cage.curtin.edu.au

[17] Lijing B., Zhengpeng Z. (2008). Application Of Point Clouds From Terrestrial 3D.

[18] Jaiswal, M. (2017). Cloud computing and Infrastructure. International Journal Of Research And Analytical Reviews, 4(2), 742-746. doi: 10.6084/m9.doi.one.IJRAR19D1251

[19] McLean A.G, (1988), Silo Design: Current and Future, Viewed 13 April 2008, Price W.F and Uren J, 2006, Surveying for Engineers, 4th Edition, Palgrave McMillan, London. Photogrammetrists, Falls Church, VA, (1980).

[20] Photogrammetry for the Modelling of Mouldboard Plough Surfaces, Biosystems Engineering (2005) 90 (4), p.397-407. Range Photogrammetry and Machine Vision, 9-51.

[21] Roberts G and Hirst L (2005). Deformation Monitoring and Analysis of Structures Using Laser Scanners, Commission 6 Engineering Surveys, FIG Working Week 2005 / TS38 Using Laser Scanning in Engineering Surveys, Viewed 6 April 2008, www.fig.net

[22] Schmid T, Schack-Kirchner H nd Hildebrand E, (2005). A Case Study Of Terrestrial Laser Scanning In Erosion Research: Calculation of Roughness and Volume Balance at a Logged Forest Site, Remote Sensing Applications, Commission www.isprs.org.

[23] Thiel K-H, Wehr A (2004) Performance capabilities of laser scanners - an overview and measurement principle analysis. In: Proceedings of the ISPRS working group VIII/2 "LaserScanners for Forest and Landscape Assessment", Freiburg, Germany, $\quad$ October $\quad 3 \quad$ - 6 . http://www.isprs.org/publications/archives.html

[24] Van Gosliga R, Lindenbergh R and Pfeifer N (2007). Deformation Analysis of a Bored Tunnel By Means Of Terrestrial Laser Scanning, www.ipf.tuwien.ac.at

[25] Vosselman G. and Maas H.-G (2010). Airborne and Terrestrial Laser Scanning// Whittles Publishing, Scotland, UK, 2010

[26] W. Boehler, M. Bordas Vicent and A. Marbs (23003). Investıgatıng Laser Scanner Accuracy, Orıgınally Presented
At The Xixth Cipa Symposium At Antalya, Turkey, 30 Sep 4 Oct 2003 